EVIDENCE BASED PUBLIC HEALTH POLICY AND PRACTICE

\title{
How much downside? Quantifying the relative harm from tobacco taxation
}

\author{
N Wilson, G Thomson, M Tobias, T Blakely
}

J Epidemiol Community Health 2004;58:451-454. doi: 10.1136/jech.2003.011528

See end of article for authors' affiliations

\section{Correspondence to:} Dr N Wilson, 367A Karori Road, Karori, Wellington, New Zealand; nwilson@ actrix.gen.nz

Accepted for publication 18 September 2003

\begin{abstract}
Objective: To estimate the loss of life expectancy attributable to tobacco taxation (via financial hardship and flow-on health effect) in New Zealand.

Design: Data were used on the gradients in life expectancy and smoking by neighbourhood socioeconomic deprivation and survey data on tobacco expenditure. Three estimates were modelled of the percentage of the crude association of neighbourhood deprivation with life expectancy that might be mediated via financial hardship: $100 \%, 50 \%$, and $25 \%$ (best estimate). From this information the impact of tobacco taxation on life expectancy was estimated.

Main results: For the total population, the estimated loss of life expectancy due to tobacco tax ranged from 0.005 years to 0.027 years. For people living in the most deprived $30 \%$ of neighbourhoods, the range was 0.009 to 0.044 years (that is, 3 to 16 days of lost life expectancy). For the total population the loss of life expectancy attributable to tobacco tax ranged from 119 to 460 times less than that attributable to deprivation. The loss of life expectancy attributable to tobacco tax was 42 to 257 times less than that attributable to smoking.

Conclusions: The estimated harm to life expectancy from tobacco taxation (via financial hardship) is orders of magnitude smaller than the harm from smoking. Although the analyses involve a number of simplistic assumptions, this conclusion is likely to be robust. Policy makers should be reassured that tobacco taxation is likely to be achieving far more benefit than harm in the general population and in socioeconomically deprived populations.
\end{abstract}

T bacco taxation is widely used to encourage quitting and deter smoking uptake. According to a recent systematic review there is "strong scientific evidence" that increasing the unit price for tobacco products is effective in increasing smoking cessation and reducing consumption. ${ }^{1} \mathrm{~A}$ review of tobacco company internal documents concludes "that price increases lead to significant reductions in overall smoking, increases in smoking cessation, and reductions in smoking prevalence, with relatively large effects on young people" ${ }^{\prime 2}$ There is evidence from the United States, ${ }^{3}{ }^{4}$ and the United Kingdom, ${ }^{5}$ that low income populations are particularly likely to reduce consumption as a result of tobacco taxation increases. Another study found that the least educated were the most price responsive. ${ }^{6}$ For these reasons tobacco taxation increases have been described by some as being "a progressive public health policy". ${ }^{7}$

However, when considering future tobacco tax increases as a tobacco control measure, the potential for increased financial hardship for low income households may deter policy makers from raising tobacco tax rates. This hardship may apply to households containing smokers who do not quit after a tax increase. One New Zealand estimate was that, for a $10 \%$ tobacco price rise, a household with a solo smoking adult with children would have to spend an average of \$NZ 70-100 more per year if they neither quit nor cut down. ${ }^{8}$ Yet concern about the tax burden on the poor from tobacco tax increases has been described as one of the economic "myths" promulgated by the tobacco industry according to a recent review of the economics of tobacco. ${ }^{7}$

Tobacco tax is also a significant source of government revenue worldwide. ${ }^{9}$ The health, political, and economic importance of tobacco tax, mean that policy makers need information on the benefits and costs to different populations from tobacco taxation. One aspect of this information is the relative gains and losses in life expectancy from tobacco taxation. To explore this issue further, we used New Zealand data to estimate the lost life expectancy attributable to tobacco taxation via financial hardship. Our estimates only consider the impact on life expectancy, not on measures of morbidity, and are indicative only.

\section{METHODS}

Life expectancy data

Life expectancy data by neighbourhood socioeconomic deprivation, and the impact of tobacco use on life expectancy by level of socioeconomic deprivation, were obtained from a study by the New Zealand Ministry of Health (table 1$).{ }^{10}$ This analysis used census data on smoking rates stratified by NZDep96 (a census based small area index of socioeconomic deprivation), estimates of the relative risk of death from all causes attributable to smoking (from the American Cancer Society CPS II study), and New Zealand mortality data for the period 1995-1997. NZDep96 is calculated for census small areas of about 100 to 150 people using nine socioeconomic variables. ${ }^{11}$ Living in a deprived neighbourhood in New Zealand is strongly associated with substantially increased mortality rates. ${ }^{12-14}$ The reference population used for determining "lost life expectancy" was the decile of neighbourhoods with the lowest level of deprivation.

\section{Tobacco expenditure data}

Household Economic Survey data for the 1996/1997 period provided expenditure data on tobacco products by household income decile. ${ }^{15}$ This was multiplied by the proportion of the tobacco retail price that was government taxation $\left(70 \%{ }^{16}\right)$. Given the possibility of under-reporting of tobacco consumption in the Household Economic Survey, we undertook a sensitivity analysis in which tobacco expenditure was doubled for the population living in the most deprived 
Table 1 Input data for estimating the impact of tobacco taxation on life expectancy in New Zealand

\begin{tabular}{|c|c|c|c|c|}
\hline & \multicolumn{2}{|c|}{ Total population } & \multicolumn{2}{|c|}{$\begin{array}{l}\text { Population living in the most deprived } 30 \% \text { of } \\
\text { neighbourhoods }\end{array}$} \\
\hline & Men & Women & Men & Women \\
\hline \multicolumn{5}{|l|}{ Life expectancy ${ }^{10}$} \\
\hline Life expectancy (LE) of total population (years) & 74.4 & 79.6 & 71.0 & 77.2 \\
\hline $\begin{array}{l}\text { Total lost LE compared with the reference population of the least } \\
\text { deprived decile (that is, decile 1) }\end{array}$ & 5.0 & 3.1 & 8.3 & 5.5 \\
\hline Tobacco use contribution to lost LE (years) $[A]$ & 1.8 & 0.8 & 3.0 & 1.3 \\
\hline $\begin{array}{l}\text { Non-tobacco contribution to lost LE (years) [B] } \\
\text { Tobacco expenditure and tax }\end{array}$ & 3.2 & 2.3 & 5.3 & 4.2 \\
\hline Proportion of average weekly household expenditure on tobacco ${ }^{15}[\mathrm{C}]^{*}$ & $1.19 \%$ & $1.19 \%$ & $1.19 \%$ & $1.19 \%$ \\
\hline $\begin{array}{l}\text { Proportion of average weekly household expenditure related to } \\
\text { tobacco tax. }{ }^{16}[D=C \times 70 \%]\end{array}$ & $0.83 \%$ & $0.83 \%$ & $0.83 \%$ & $0.83 \%$ \\
\hline
\end{tabular}

neighbourhoods (that is, up from $1.2 \%$ to $2.4 \%$ of household spending).

\section{Calculation of harm from tobacco tax}

Table 2 shows the crude estimates of lost life expectancy attributable to neighbourhood socioeconomic deprivation and to smoking for the different population groups. These estimates are crude in that they do not allow for confounding of the association of socioeconomic deprivation with mortality, such as education, personality factors, and so on. We had to make two steps or assumptions to use the deprivation data. Firstly, we assumed that the association of deprivation (rank) with life expectancy approximated that of income (rank) with life expectancy. This assumption is supported by previous work that finds that for most causes of death the rank association of household income with mortality is similar to that for deprivation in New Zealand. ${ }^{14}{ }^{17}$ Secondly, we then had to estimate what fraction of the income association with mortality or life expectancy might be the unconfounded component. Such estimation is problematic in any observation epidemiology. ${ }^{18-21}$ However, New Zealand data suggest that perhaps a quarter to a third of the observed crude association of income with mortality might be the causal component (personal communication Amanda D'Souza, Wellington, May 2003). ${ }^{17}$ Such estimates concur with research on other social and health outcomes. ${ }^{22}$ Thus, our best estimate was that $25 \%$ of the crude association of neighbourhood socioeconomic deprivation approximates the causal income association with life expectancy. We also modelled $50 \%$ and $100 \%$ as more extreme tests of the possible adverse impact of tobacco tax on health via financial hardship.

We then multiplied the lost life expectancy from financial hardship for each population group by the proportion of household spending associated with tobacco tax. The results were the estimated loss of life expectancy attributable to tobacco taxation for each population group, for both smokers and non-smokers.

The collective harm in terms of years of life lost was based on the total number of deaths for 1999 in New Zealand ( 14348 deaths in men and 13873 deaths in women ${ }^{23}$ ).

\section{RESULTS}

\section{The burden of lost life expectancy from tobacco tax}

For the total population the estimated overall burden from tobacco tax on life expectancy ranged from 0.005 years to 0.027 years (that is, two to nine days of lost life expectancy) (table 2). For people living in the most deprived $30 \%$ of neighbourhoods the equivalent range was from 0.009 to 0.044 years (that is, 3 to 16 days of lost life expectancy). Men living in the most deprived three deciles were estimated to have the highest burden (at 1.6 times that of the average man and 2.3 times that of the average women). When assuming a $50 \%$ under-reporting of tobacco consumption in the Household Economic Survey (for the deprived population) the life expectancy loss ranged from 0.018 years to 0.089 years (that is, 7 to 32 days).

For the whole New Zealand population, the lost life expectancy from tobacco tax was estimated to be equivalent in numerical terms to the loss of 2.3 to 8.7 lives per year. (Assuming an average life expectancy of 75 years in length).

\section{Comparisons with the burdens from deprivation and smoking}

The overall loss of life expectancy attributable to neighbourhood socioeconomic deprivation ranged from 119 to 460 times that attributable to tobacco tax for the total population (table 2). For those living in the most deprived $30 \%$ of neighbourhoods, the equivalent range was 120 to 482 times.

The results also indicate that the loss of life expectancy attributable to smoking was 42 to 257 times greater than that attributable to tobacco tax. For those living in the most deprived neighbourhoods the equivalent range was 37 to 273 times (with the former figure being for women and assuming that $100 \%$ of deprivation is mediated through financial hardship). When assuming a 50\% under-reporting of tobacco consumption in the Household Economic Survey, the equivalent range for the deprived population was 18 to 136 times.

\section{DISCUSSION}

This analysis has a number of limitations. In particular the uncertainty around financial hardship as a pathway in contributing to deprivation associated lost life expectancy (hence our modelling in the $25 \%$ to $100 \%$ range). We also have assumed that this relation is completely linear. Work in progress by one of the authors (TB) using linked census mortality data is finding that the rank of income is (mostly) linearly associated with mortality risk. Furthermore, this linearity is preserved (although the strength of the steepness of the linear association is attenuated by over half) when adjusting for potential confounds of the income-mortality association. As the deprivation scale essentially ranks people, we have made the assumption that this rank association is substitutable for the rank income association. Another issue is that it takes time for income to "get under the skin" and influence health or disease processes. We have not modelled these lag times in this paper given the complexities involved. However, the key finding that the estimated harm to life expectancy from tobacco taxation (via financial hardship) is orders of magnitude smaller than the harm from smoking, is 
Table 2 Estimated impact of tobacco taxation on life expectancy in New Zealand and its comparison with deprivation and smoking

\begin{tabular}{|c|c|c|c|c|}
\hline & \multicolumn{2}{|c|}{ Total population } & \multicolumn{2}{|c|}{$\begin{array}{l}\text { Population living in the most } \\
\text { deprived } 30 \% \text { of neighbourhoods }\end{array}$} \\
\hline & Men & Women & Men & Women \\
\hline \multicolumn{5}{|l|}{$\begin{array}{l}\text { Most extreme case-assuming } 100 \% \text { of deprivation is mediated through financial } \\
\text { hardship }\end{array}$} \\
\hline Lost LE attributed to tobacco taxation (years) $[E=B \times D]^{*}$ & 0.027 & 0.019 & 0.044 & 0.035 \\
\hline $\begin{array}{l}\text { Ratio of harm to LE from deprivation (excluding tobacco) compared with tobacco tax } \\
{[\mathrm{F}=\mathrm{B} / \mathrm{E}]}\end{array}$ & 119 & 121 & 120 & 120 \\
\hline $\begin{array}{l}\text { Ratio of harm to LE from smoking compared with tobacco tax }[G=A / E] \\
\text { Assuming } 50 \% \text { of deprivation is mediated through financial hardship }\end{array}$ & 67 & 42 & 68 & 37 \\
\hline 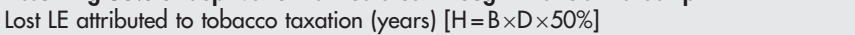 & 0.013 & 0.010 & 0.022 & 0.017 \\
\hline $\begin{array}{l}\text { Ratio of harm to LE from deprivation (excluding tobacco) compared with tobacco tax } \\
{[I=B / G]}\end{array}$ & 246 & 230 & 241 & 247 \\
\hline $\begin{array}{l}\text { Ratio of harm to LE from smoking compared with tobacco tax }[\mathrm{J}=\mathrm{A} / \mathrm{G}] \\
\text { Best estimate-assuming } 25 \% \text { of deprivation is mediated through financial hardship }\end{array}$ & 138 & 80 & 136 & 76 \\
\hline Lost LE attributed to tobacco taxation (years) $[K=B \times D \times 25 \%]$ & 0.007 & 0.005 & 0.011 & 0.009 \\
\hline $\begin{array}{l}\text { Ratio of harm to LE from deprivation (excluding tobacco) compared with tobacco tax } \\
{[\mathrm{L}=\mathrm{B} / \mathrm{I}]}\end{array}$ & 457 & 460 & 482 & 467 \\
\hline Ratio of harm to LE from smoking compared with tobacco tax $[M=A / I]$ & 257 & 160 & 273 & 144 \\
\hline
\end{tabular}

unlikely to be greatly changed by improved modelling of the income-mortality association (should this modelling be possible).

Another limitation is that we did not have adequate data to stratify the population further by ethnicity. In New Zealand, Maori and Pacific peoples are over-represented in deprived populations, and (Maori particularly) have much higher levels of tobacco use than the Pakeha/European population. Further research on the financial hardship from tobacco taxation between different ethnic groups is therefore a research priority.

We undertook a sensitivity analysis to investigate the possibility of under-reporting of the household expenditure on tobacco in the Household Economic Survey. Nevertheless, the level of under-reporting could conceivably be even greater than the $50 \%$ we assumed in the sensitivity analysis. Furthermore, as our analysis was an ecological one, using data for whole populations, the probable larger effects from tobacco taxation on those in households with smokers are not shown.

Despite these various limitations, this analysis still provides an indication of the potential quantifiable harm to life expectancy attributable to tobacco tax-the first for any population in the world that we know of. The results suggest that such harm is not trivial, is inequitable, and is worthy of concern from a public health perspective. Nevertheless, the burden of harm from tobacco tax seems to be small compared with that from deprivation overall and from smoking overall. The ratio of harm (tax to smoking) was lowest among women in the most deprived three deciles. Yet using the most extreme assumptions for this population (the 100\% scenario and doubling reported tobacco expenditure) the harm to this population from smoking was still 18 times greater that that attributable to tobacco taxation. This should provide

\section{Key points}

- Tobacco taxation is estimated to be a significant cause of lost life expectancy at a whole population level and for relatively socioeconomically deprived populations.

- The burden of harm from tobacco taxation was found to be small compared with that from socioeconomic deprivation overall, and from smoking overall. reassurance to policy makers that tobacco taxation is likely to be achieving far more benefit than harm in comparatively deprived populations. Even so, the optimal level of further tobacco tax increases should ideally be informed by marginal analyses of the benefits and costs to both the whole population and deprived populations. Such analyses ideally need to consider health impacts (both morbidity and life expectancy) and financial hardship imposed on individuals and households.

\section{Reducing the harm from tobacco tax}

While tobacco tax policy outcomes are complex, we suggest that the best long term mechanism to reduce the harm from tobacco tax is likely to be the reduction of tobacco consumption per smoker and overall smoking prevalence in the population. This is achievable through having a strong and comprehensive tobacco control strategy (including high tobacco prices, intensive mass media campaigns, support for smoking cessation, and possibly modifying tobacco constituents). These strategies should be well funded through the use of a substantial proportion of tobacco taxation revenue (rather than spending all this revenue on general purposes). Reducing tobacco tax does not seem a viable option, given the substantial international evidence that lower tobacco prices could erode the effectiveness of other tobacco control interventions. ${ }^{24} 25$

Reducing the inequality in the burden from tobacco tax is also desirable. The use of tobacco tax revenue to increase the funding of tobacco control would tend to a decrease in

\section{Policy implications}

- Tobacco taxation is likely to be achieving far more benefit than harm in relatively socioeconomically deprived populations, given the much greater harm from smoking relative to tobacco taxation.

- Policy makers need to minimise the potential financial hardship to socioeconomically deprived households that is attributable to tobacco taxation. This could be assisted by a stronger focus within tobacco control programmes on reaching those relatively socioeconomically deprived populations who have the highest smoking rates. 
tobacco related inequity in developed nations, given the higher smoking rates for those most socioeconomically deprived. A further solution is to include in national tobacco control programmes a stronger focus on reaching populations of greatest need using culturally appropriate interventions. In the New Zealand context, this may mean expanding tobacco control programmes that are designed for lower socioeconomic groups or Maori (for example, mass media campaigns, ${ }^{26}$ the Aukati Kaipaipa smoking cessation programmes and the number of Maori quit advisers working for the national Quitline service). Evidence from other countries points to the effectiveness of reducing out of pocket expenses for smoking cessation interventions ${ }^{1}$ (for example, nicotine replacement therapy) and the use of smoking cessation contests to reach low income smokers. ${ }^{27}$

\section{DISCLAIMER}

The views of the authors do not necessarily reflect the views of their employing organisations-including the New Zealand Ministry of Health.

\section{Authors' affiliation}

N Wilson, Public health physician, Wellington, New Zealand

G Thomson, T Blakely, Department of Public Health, Wellington School

of Medicine and Health Sciences, University of Otago, New Zealand

M Tobias, New Zealand Ministry of Health, Wellington

Funding: none.

Conflicts of interest: none declared.

\section{REFERENCES}

1 Hopkins DP, Briss PA, Ricard CJ, et al. Reviews of evidence regarding interventions to reduce tobacco use and exposure to environmental tobacco smoke. Am J Prev Med 2001;20(2S):16-66.

2 Chaloupka FJ, Cummings KM, Morley CP, et al. Tax, price and cigarette smoking: evidence from the tobacco documents and implications for tobacco company marketing strategies. Tobacco Control 2002;1 1(suppl 1):i62-72.

3 Farrelly MC, Bray JW. Office on Smoking and Health. Response to increases in cigarette prices by race/ethnicity, income and age groups-United States, 1976-1993. MMWR 1998;47:605-9.

4 Meier K, Licari M. The effect of cigarette taxes on cigarette consumption, 1955 through 1994. Am J Public Health 1997;87:1126-30.

5 Townsend JL, Roderick P, Cooper J. Cigarette smoking by socioeconomic group, sex and age: effects of price, income, and health publicity. BMJ 1994:309:923-6.

6 Chaloupka FJ. Rational addictive behavior and cigarette smoking. J Political Economy 1991;99:722-42.
7 Warner KE. The economics of tobacco: myths and realities. Tobacco Control 2000;9:78-89

8 Thomson G, O'Dea D, Wilson N, et al. The effects of tobacco tax increases on Maori and low-income families. Wellington: Department of Public Health, Wellington School of Medicine, University of Otago, 2000:29,30. http:// www.wnmeds.ac.nz/academic/dph/Tobacco/FinancialEffects.Doc (accessed 27 Apr 2003).

9 Mackay J, Eriksen M. The tobacco atlas. Geneva: World Health Organisation, 2002:103-9.

10 Tobias M, Cheung J. Inhaling inequality: tobacco's contribution to health inequality in New Zealand (Public Health Intelligence Occasional Bulletin no 7). Wellington: Ministry of Health, 2001. Http://www.moh.govt.nz/ moh.nsf/ea6005dc347e7bd44c2566a40079ae6f/ eb38a31c067f8776cc256af0000f6fle/ \$FILE/Inhalinglnequality.pdf (accessed 27 Apr 2003).

11 Salmond C, Crampton P. NZDep96-what does it measure? Social Policy Journal of New Zealand 2001;17:82-100.

12 Salmond C, Crampton P. Deprivation and health. In: Howden-Chapman P, Tobias M, eds. Social inequalities in health: New Zealand 1999. Wellington: Ministry of Health, 2000:9-64.

13 Tobias M, Jackson G. Avoidable mortality in New Zealand, 1981-97. Aust N Z J Public Health 2001;25:12-20.

14 Blakely T, Woodward A, Pearce N, et al. Socio-economic factors and mortality among 25-64 year olds followed from 1991 to 1994: The New Zealand census-mortality study. N Z Med J 2002;115:93-7.

15 Statistics New Zealand. Household economic survey standard tables 1996/ 1997. Wellington: Statistics New Zealand, 1997:11.

16 New Zealand Government. Tax review 2001. Issues paper. Wellington: New Zealand Government, 2001:51.

17 Blakely T. The New Zealand census-mortality study: socioeconomic inequalities and adult mortality 1991-94. Wellington: Ministry of Health, 2002:258. http://www.wnmeds.ac.nz/nzcms-info.html (accessed 10 May 2003).

18 Robins J, Greenland S. Identifiability and exchangeability for direct and indirect effects. Epidemiology 1992;3:143-55.

19 Poole C, Kaufman J. What does standard adjustment for downstream mediators tell us about social effect pathways? [Abstract]. Am J Epidemiol 2000;151:208.

20 Cole S, Hernán M. Fallibility in estimating direct effects. Int J Epidemiol 2002;31:163-5.

21 Blakely T. Estimating direct and indirect effects: fallible in theory, but in the real world? Int J Epidemiol 2002;31:166-7.

22 Mayer S. What money can't buy: family income and children's life chances. Cambridge, MA: Harvard University Press, 1997.

23 NZ Health Information Service. Mortality and demographic data 1998. Wellington: Ministry of Health. http://www.nzhis.govt.nz/stats/ mortstats.html (accessed 27 Apr 2003)

24 Jha P, Chaloupka FJ. The economics of global tobacco control. BMJ 2000;21:358-61.

25 Hamilton VH, Levinton C, St Pierre Y, et al. The effect of tobacco tax cuts on cigarette smoking in Canada. Can Med Assoc J 1997;156:187-91.

26 Waa A, Grigg M. "Its about whanau": views of smokers and whanau. In: Proceedings of the tobacco control research symposium, September 2002. Wellington: Health Sponsorship Council, 2003:19-21.

27 Bains N, Pickett W, Hoey J. The use and impact of incentives in populationbased smoking cessation programs: a review. Am J Health Promot 1998;12:307-20. 